\title{
Utilização da albumina na citologia esfoliativa em pacientes com conjuntivite alérgica
}

\author{
Use of albumin in exfoliativecytology in patients with allergic conjunctivitis
}

\author{
Haroldo de Lucena Bezerra ${ }^{1}$ \\ Luiz Vicente Rizzo ${ }^{2}$ \\ Maria Cecília Zorat $\mathrm{Yu}^{3}$ \\ Denise de Freitas ${ }^{4}$
}

Este trabalho é inédito e parte integrante da Tese apresentada ao Curso de Pós-graduação em Oftalmologia da Universidade Federal de São Paulo para obtenção do Título de Doutor em Medicina-Oftalmologia. Foi desenvolvido no Setor de Doença Externa Ocular e Córnea do Departamento de Oftalmologia da Universidade Federal de São Paulo - UNIFESP.

${ }^{1}$ Pós-graduando, nível Doutorado, do Departamento de Oftalmologia da Universidade Federal de São Paulo UNIFESP.

${ }^{2}$ Professor da Disciplina de Imunologia e Chefe do Laboratório de Imunologia Clínica do Instituto de Ciências Biomédicas da Universidade de São Paulo - USP.

${ }^{3}$ Biomédica do Laboratório de Doença Externa Ocular e

Córnea do Departamento de Oftalmologia da Universidade Federal de São Paulo - UNIFESP.

${ }^{4}$ Livre Docente, Professora Doutora e Chefe do Setor de Doença Externa Ocular e Córnea do Departamento de Oftalmologia da Universidade Federal de São Paulo UNIFESP.

Endereço para Correspondência: Haroldo de Lucena Bezerra - Rua Profa. Maria Sales 500/42 - João Pessoa (PB) CEP 58039-130 - e-mail: hdlucena@uol.com.br Recebida para análise em 03.06.2002

Versão revisada recebida em 22.01.2003 Aprovação em 07.04.2003

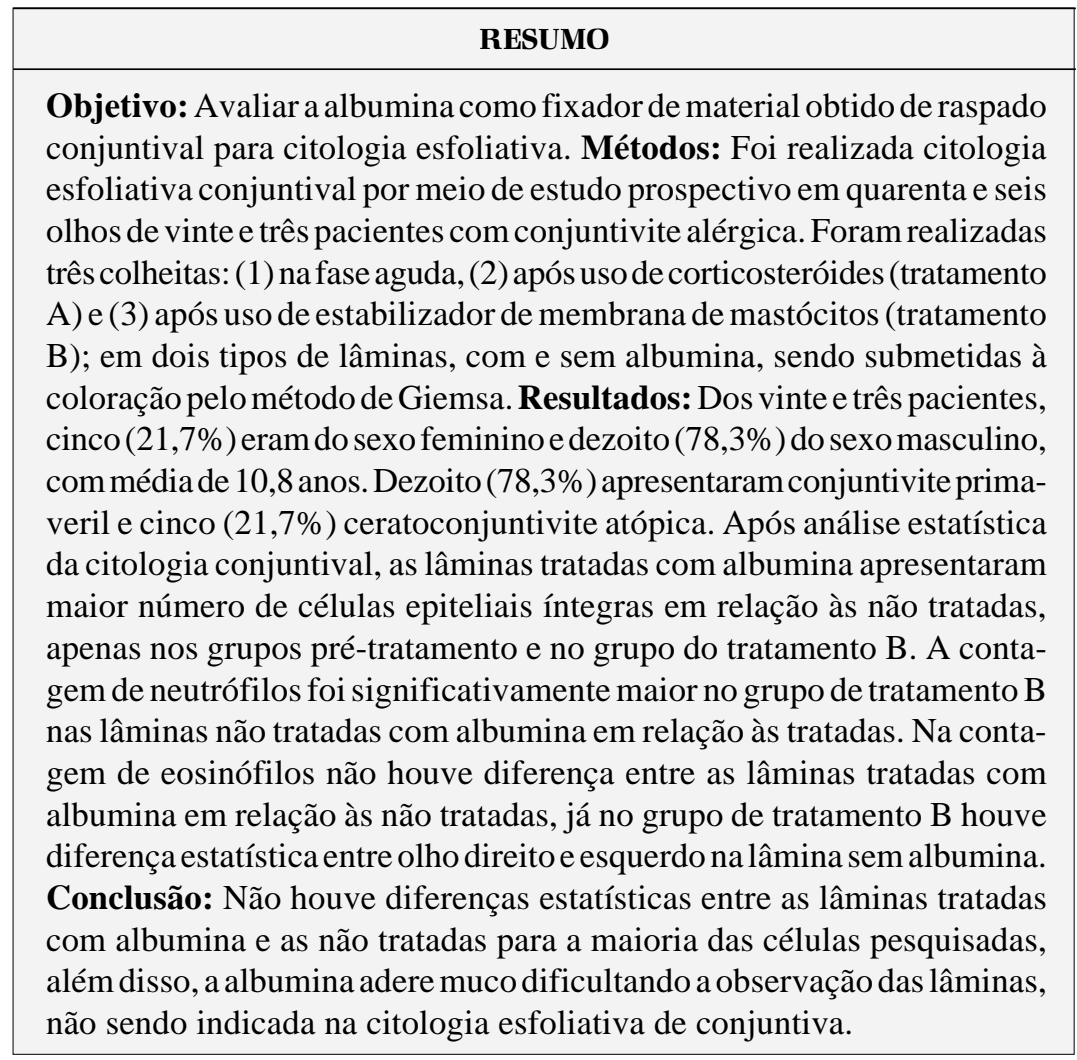

Descritores: Conjuntiva/citologia; Conjuntivite alérgica/diagnóstico; Albuminas; Técnicas citológicas/métodos

\section{INTRODUÇÃO}

A citologia tem sido usada nas diversas especialidades médicas como método de diagnóstico principalmente na ginecologia, no diagnóstico de entidades malignas do colo uterino; na hematologia, no diagnóstico de anemias e leucemias, e nas doenças infecciosas, principalmente nas meningites, através do estudo do fluido cérebro-espinhal, com grande importância clínica na elucidação diagnóstica e no prognóstico ${ }^{(1)}$.

Há três modalidades de técnica citológica: [1] esfregaços de secreções e líquidos orgânicos (citologia esfoliativa), [2] esfregaços de biópsias por aspiração e [3] decalque ("imprint”) da superfície de corte de peças cirúrgicas ou de autópsias ${ }^{(2)}$.

O diagnóstico da conjuntivite alérgica é clínico, podendo ser confirmado através da citologia ${ }^{(3)}$. Na conjuntiva utilizamos a citologia esfoliativa ${ }^{(4)}$. 
Uma vez colhido um material biológico este deve ser fixado para que não ocorra a sua deterioração. Em citologia esfoliativa, os álcoois são o fixador mais adequado e econômico ${ }^{(2)}$.

Os esfregaços podem aderir melhor às lâminas passandose previamente sobre as mesmas cola de gelatina ou albumi$\mathrm{na}^{(2)}$. Esse procedimento é utilizado de rotina na anatomia patológica, sendo também utilizado em esfregaços de células do colo uterino ${ }^{(5-6)}$. A albumina utilizada nesses esfregaços é conhecida como albumina de Mayer e é obtida pela mistura de uma parte de glicerina pura com uma parte de clara de ovos de galinhas $^{(7)}$.

O Giemsa é o corante mais utilizado em citologia esfoliativa para o estudo das doenças externas oculares. É útil para o estudo da morfologia epitelial e dos diferentes padrões de células inflamatórias ${ }^{(4)}$.

Os tipos celulares mais importantes que podem ser evidenciados na citologia ocular conjuntival são as células epiteliais, células caliciformes, células epiteliais multinucleadas, neutrófilos, mononucleares (linfócitos e monócitos), eosinófilos e basófilos/mastócitos ${ }^{(1,8)}$.

Em 1903, Herbert foi o primeiro autor a chamar atenção para a eosinofilia conjuntival no diagnóstico de conjuntivite alérgi$\mathrm{ca}^{(9)}$, e, até hoje, o diagnóstico laboratorial de alergia ocular freqüentemente baseia-se na presença de eosinófilos na citologia conjuntival ${ }^{(10-11)}$. Os neutrófilos também são encontrados na citologia da conjuntivite alérgica ${ }^{(12-13)}$. A presença de neutrófilos na conjuntivite alérgica foi primeiramente citada em $1955^{(14)}$.

O objetivo do presente trabalho é avaliar a albumina como fixador de material obtido de raspado conjuntival para citologia esfoliativa em pacientes com conjuntivite alérgica.

\section{MÉTODOS}

Foi realizado um estudo prospectivo de quarenta e seis olhos de vinte e três pacientes com diagnóstico clínico de conjuntivite alérgica primaveril ou atópica no Setor de Doença Externa Ocular e Córnea do Departamento de Oftalmologia da Universidade Federal de São Paulo - UNIFESP/EPM, após aprovação do Comitê de Ética da Instituição.

Os pacientes foram submetidos à propedêutica oftalmológica completa e em seguida o exame citológico obtido do raspado conjuntival. Foram realizadas três colheitas de material conjuntival. A primeira colheita foi realizada na consulta inicial, quando os pacientes estavam em fase de agudização do quadro de conjuntivite e sem uso de medicação tópica ou sistêmica. Após a colheita, os pacientes foram medicados com colírio de dexametasona a $0,1 \%$ (Tratamento $\mathrm{A}$ ). O retorno do paciente deu-se no $16^{\circ}$ dia do início do estudo, sendo então submetido à segunda colheita. Neste momento, suspendia-se o uso da dexametasona tópica e medicava-se com um estabilizador de membrana de mastócito, a lodoxamida a 0,1\%, (Tratamento B). No $31^{\circ}$ dia de estudo, o paciente retornava para avaliação, realizando-se a última colheita.
Dois tipos de lâminas foram empregados para a realização dos esfregaços. As lâminas tipo 1 foram preparadas de acordo com a rotina pré-estabelecida no laboratório, ou seja, lâminas limpas e estéreis. As tipo 2, além de limpas e estéreis, receberam uma fina camada de albumina, durante o processo de fixação do esfregaço.

No raspado conjuntival padronizou-se que nos pacientes com diagnóstico clínico de conjuntivite primaveril far-se-ia o raspado da conjuntiva tarsal superior, e para aqueles com diagnóstico de conjuntivite atópica, o raspado da inferior. Alternou-se a ordem de colocação do material obtido com o raspado na lâmina com e sem albumina. Ou seja, se em um paciente foi colocado o primeiro esfregaço na lâmina sem albumina, no paciente seguinte colocava-se o primeiro esfregaço na lâmina com albumina e assim por diante.

Imediatamente após a realização do esfregaço, as lâminas foram submetidas à coloração pelo método de Giemsa ${ }^{(15)}$.

A análise dos esfregaços foi realizada por dois observadores de laboratórios distintos de maneira mascarada. Na análise estatística dos resultados foram aplicados os testes de Wilcoxon e Spearman ${ }^{(16)}$. Fixou-se em 0,05 ou $5 \%(\alpha \leq 0,05)$ o nível de rejeição da hipótese de nulidade.

\section{RESULTADOS}

Foram examinados vinte e três pacientes, dos quais cinco $(21,7 \%)$ eram do sexo feminino e dezoito $(78,3 \%)$ do sexo masculino. As idades variaram de seis a dezenove anos, com média de 10,8 anos. Dentre os tipos de conjuntivite alérgica observou-se que dezoito (78,3\%) apresentaram diagnóstico clínico de conjuntivite primaveril e cinco $(21,7 \%)$ de ceratoconjuntivite atópica.

Em relação à citologia conjuntival, na avaliação da diferença na contagem de células epiteliais íntegras para lâminas com e sem albumina não houve diferença estatisticamente significante entre os olhos em todos os grupos. Os dados das lâminas foram então agrupados e as médias de olhos direito e esquerdo foram utilizadas para comparação entre lâminas 1 e 2 . Assim, as lâminas tratadas com albumina apresentaram maior número de células epiteliais íntegras em relação às não tratadas, apenas nos grupos pré-tratamento e no grupo do tratamento B apresentaram significância estatística (Gráfico 1).

$\mathrm{Na}$ avaliação da diferença na contagem de células epiteliais em degeneração para lâminas com e sem albumina não houve diferença estatisticamente significante entre os olhos em todos os grupos. A comparação entre lâminas 1 e 2 foi feita com as médias de olhos direito e esquerdo. Não houve diferença na contagem de células epiteliais em degeneração entre as lâminas tratadas com albumina em relação às não tratadas. $\mathrm{O}$ mesmo ocorreu para células epiteliais degeneradas, para os monócitos e os linfócitos.

$\mathrm{Na}$ avaliação da diferença na contagem do número de neutrófilos para lâminas com e sem albumina não houve dife- 
rença estatisticamente significante entre os olhos em todos os grupos, fazendo-se a comparação entre lâminas 1 e 2 com as médias de olhos direito e esquerdo. Não houve diferença estatística na contagem dos neutrófilos entre as lâminas tratadas com e sem albumina nos grupos pré-tratamento e tratamento A. No entanto, a contagem de células foi significativamente maior no grupo de tratamento B nas lâminas não tratadas com albumina em relação às tratadas (Gráfico 2).

A avaliação da diferença na contagem de eosinófilos para lâminas com e sem albumina não mostrou diferença estatisticamente significante entre os olhos nos grupos pré-tratamento e tratamento A. No grupo de tratamento B houve diferença estatística entre olho direito e esquerdo na lâmina sem albumina. Porém, ao se realizar o teste de Spearman, observou-se grande correlação entre os dois grupos (olho direito e esquerdo, lâmina 1) com valor de $\mathrm{p}<0,01$ (Tabela 1). Portanto, a comparação entre lâminas 1 e 2 foi feita com as médias de olhos direito e esquerdo, em todos os grupos, e não houve diferença na contagem de eosinófilos entre as lâminas tratadas com albumina em relação às não tratadas (Gráfico 3).

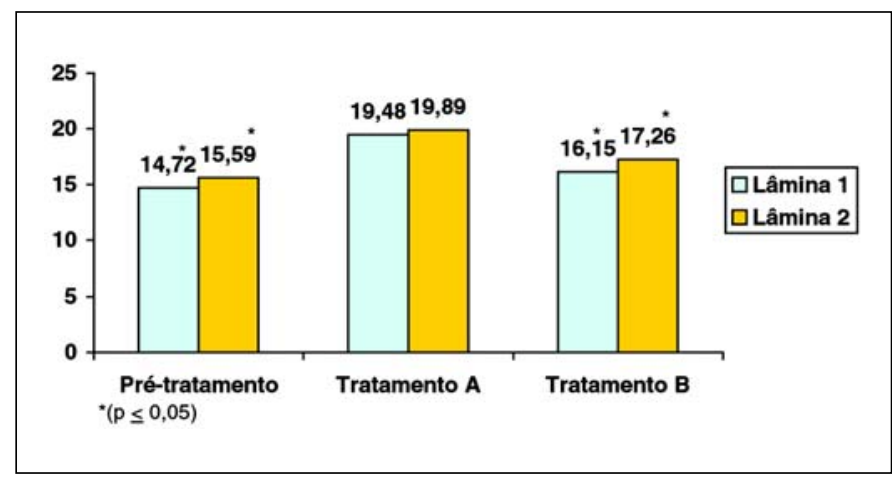

Gráfico 1 - Média do número de células epiteliais íntegras presentes nas lâminas preparadas sem (Lâmina 1) e com albumina (Lâmina 2), dos olhos de pacientes com conjuntivite alérgica, coletadas no período pré-tratamento e após o uso de corticosteróides (Tratamento A) e estabilizador de membrana de mastócitos (Tratamento B)

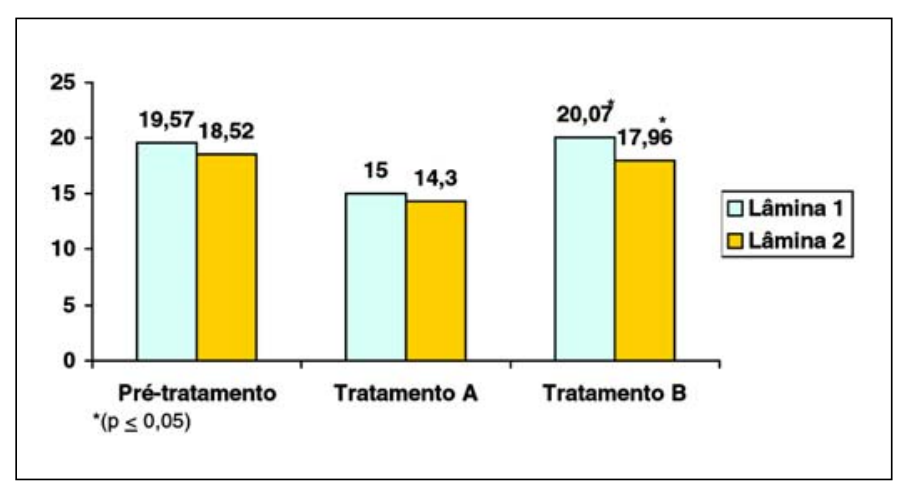

Gráfico 2 - Média do número de neutrófilos presentes nas lâminas preparadas sem (Lâmina 1) e com albumina (Lâmina 2), dos olhos de pacientes com conjuntivite alérgica, coletadas no período prétratamento e após o uso de corticosteróides (Tratamento A) e estabilizador de membrana de mastócitos (Tratamento B)

\section{DISCUSS ÃO}

Entre os pacientes com conjuntivite primaveril 78,3\% eram do sexo masculino e $21,7 \%$ eram do sexo feminino, numa proporção de aproximadamente 4:1. A faixa etária variou de seis a dezenove anos, com média de 10,8 anos. Os dados demográficos dos nossos pacientes com conjuntivite primaveril coincidem com os da literatura ${ }^{(17-18)}$. Dentre os pacientes com ceratoconjuntivite atópica a média de idade foi de 13,6 anos, valor este abaixo ao que é observado na literatura como pico de incidência, mas dentro do que é esperado para início da doença ${ }^{(3,19-20)}$. A ausência de pacientes com ceratoconjuntivite atópica em faixa etária maior pode se dever ao fato dos nossos pacientes encontrarem-se na fase inicial da doença, além disso esta ceratoconjuntivite, em nossa região, provavelmente comporta-se de maneira diferente, uma vez que não há dados epidemiológicos nacionais referentes a esta doença.

Para o estudo citológico, as células epiteliais foram classificadas em íntegras, em degeneração e degeneradas, na tentativa de representar a magnitude do processo inflamatóriodestrutivo $^{(13)}$. As células epiteliais degeneradas seriam então a representação maior de alterações de conformação anatômica em virtude do processo inflamatório. Durante o processo inflamatório, as células epiteliais da conjuntiva e da córnea tornam-se hipertrofiadas e facilmente desprendem-se, sem apresentar alterações marcantes ${ }^{(21)}$.

Os neutrófilos são células efetoras em muitas respostas inflamatórias, como nas conjuntivites agudas e crônicas ${ }^{(14,22)}$, principalmente nas conjuntivites causadas por bactérias e fungos ${ }^{(23)}$. Entretanto Kimura \& Thygeson em 1955, mencionaram em seu estudo que uma reação eosinofílica da conjuntiva poderia ser acompanhada de uma reação neutrofílica em pacientes com conjuntivite alérgica na ausência de afecção bacteriana associada ${ }^{(14)}$.

O eosinófilo é a principal célula envolvida no diagnóstico da alergia ocular, sendo considerada a célula característica da inflamação alérgica ${ }^{(22)}$. A ausência de eosinófilo no raspado conjuntival não exclui o diagnóstico de alergia ocular ${ }^{(24-26)}$. Constatamos isto neste estudo quando se observou que alguns pacientes não apresentaram eosinófilos na citologia nas três etapas de coleta do raspado conjuntival. Apesar de não encontrados no esfregaço do raspado conjuntival, é possível evidenciar eosinófilos na substância própria da conjuntiva de indivíduos com conjuntivite alérgica, não sendo necessariamente evidenciados no epitélio( ${ }^{(24,26)}$.

Utilizamos a albumina em lâminas com o objetivo de avaliála como fixador de material do raspado conjuntival. A albumina é empregada principalmente nos esfregaços de citologia esfoliativa de colo uterino, para uma melhor aderência do material colhido à lâmina ${ }^{(1-2,5-6)}$. Apesar da citologia das células epiteliais íntegras mostrar uma maior quantidade de células nas lâminas com albumina, isto se deu apenas na fase de prétratamento e tratamento $\mathrm{B}$, já com os neutrófilos ocorreu o 


\begin{tabular}{|c|c|c|c|c|}
\hline Variável & Grupo & Correlação & $\mathbf{R}$ & $\mathbf{P}$ \\
\hline Células epiteliais íntegras & Pré-Tratamento & Lâmina 1 x Lâmina 2 & 0,89 & $<0,01$ \\
\hline Células epiteliais íntegras & Tratamento B & Lâmina 1 x Lâmina 2 & 0,88 & $<0,01$ \\
\hline Neutrófilos & Tratamento B & Lâmina 1 x Lâmina 2 & 0,75 & $<0,01$ \\
\hline Eosinófilos & Tratamento B & Olho direito $\mathrm{x}$ Olho esquerdo & 0,87 & $<0,01$ \\
\hline
\end{tabular}

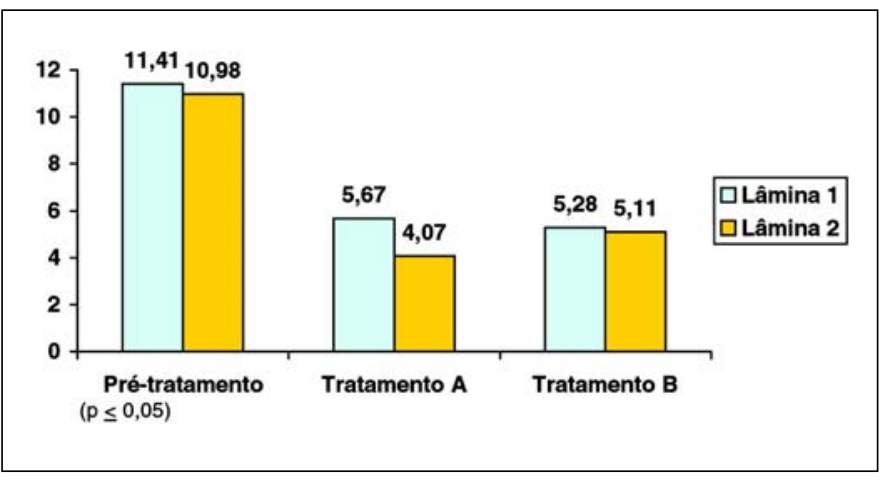

Gráfico 3 - Média do número de eosinófilos presentes nas lâminas preparadas sem (Lâmina 1) e com albumina (Lâmina 2), dos olhos de pacientes com conjuntivite alérgica, coletadas no período prétratamento e após o uso de corticosteróides (Tratamento A) e estabilizador de membrana de mastócitos (Tratamento B)

inverso, a quantidade dessas células foi maior em lâminas não albuminadas, somente no tratamento B. Nossos resultados revelaram que não houve importante favorecimento na utilização das lâminas com albumina em relação às sem albumina para a maioria das células pesquisadas. Não há dados na literatura sobre o uso da albumina em esfregaços de citologia conjuntival ou qualquer outra citologia ocular, não nos permitindo uma comparação maior e melhor com outros estudos. Deve-se salientar ainda que o muco tem uma maior aderência em lâminas albuminizadas podendo assim dificultar a observação do esfregaço ${ }^{(2)}$.

Na contagem de eosinófilos houve diferença estatística entre os olhos direito e esquerdo, o que nos permitiria sugerir uma assimetria de acometimento das conjuntivas, o que é citado na literatura ${ }^{(3)}$, entretanto, isso só ocorreu após a administração de estabilizador de membrana de mastócito na lâmina não albuminizada. Ao realizar o teste de Spearman, observou-se grande correlação e dependência entre as medidas (olho direito e esquerdo), não nos permitindo afirmar que existe assimetria de acometimento ocular na conjuntivite alérgica.

Optamos pelo uso do corante de Giemsa por ser o mais empregado na citologia esfoliativa das doenças externas oculares $^{(4,15)}$ e porque outros corantes têm sido aplicados mais especificamente para outras doenças como, por exemplo, o corante de Papanicolaou classicamente utilizado na identificação de neoplasias, o corante de Wright normalmente empregado para preparações hematológicas, entre outros ${ }^{(1)}$. O muco possui a propriedade de corar-se com o método de Giemsa, e por apresentar maior aderência em lâminas albuminizadas dificulta ainda mais a observação do esfregaço ${ }^{(2)}$.

\section{CONCLUSÃO}

Não houve diferenças estatísticas entre as lâminas tratadas com albumina e as não tratadas para a maioria das células pesquisadas, além disso, a albumina adere muco dificultando a observação das lâminas, não sendo indicada na citologia esfoliativa de conjuntiva.

\section{ABSTRACT}

Purpose: To evaluate albumin as fixative material of conjunctival scrapings for exfoliative cytology. Methods: Conjunctival exfoliative cytology was performed through a prospective study in forty-six eyes of twenty-three patients with clinical diagnosis of allergic conjunctivitis. Three scrapings were performed: (1) in the pretreatment period, (2) after use of corticosteroids (treatment A) and (3) after use of mast cell stabilizer (treatment B); in two types of smears, with and without albumin, which were then submitted to staining by the Giemsa method. Results: Of the twenty-three patients, five (21.7\%) were female and eighteen (78.3\%) male, with an age average of 10.8 years. Eighteen (78.3\%) presented vernal conjunctivitis and five (21.7\%) atopic keratoconjunctivitis. By the statistical analysis of the conjunctival cytology, the smears treated with albumin presented a larger number of intact epithelial cells in relation to the nontreated, only in the pretreatment and in the B treatment groups. The number of neutrophils was significantly greater in the $\mathrm{B}$ treatment group than in the smears not treated with albumin in relation to the treated ones. Regarding the number of eosinophils there was no difference between the smears treated with albumin in relation to the nontreated, while in the $\mathrm{B}$ treatment group there was a statistical difference between the right and left eye regarding smears without albumin. Conclusion: There were no statistical differences between smears treated with albumin and those not treated for most researched cells; in addition, albumin adheres mucus hindering the observation of smears, and thus is not indicated for conjunctival exfoliative cytology.

Keywords: Conjunctiva/cytology; Conjunctivitis, allergic/ diagnosis; Albumins; Cytological techniques/methods 


\section{REFERÊNCIAS}

1. Byrne KA, Tabbara KF, Burd EM, Hyndiuk RA. Diagnostic microbiology and cytology of the eye. Newton: Butterworth-Heinemann; 1995.

2. Michalany J. Técnica citológica aplicada à anatomia patológica. In: Michalany J. Técnica histológica em anatomia patológica: com instruções para o cirurgião, enfermeiro e citotécnico. São Paulo: Michalany; 1990. p.40-9.

3. Friedlaender MH. Conjunctivitis of allergic origin: clinical presentation and differential diagnosis. Surv Ophthalmol 1993;38 (Suppl):105-14.

4. Stenson S. Cytologic Diagnosis. A. The anterior segment cytopathology. In: Karcioglu ZA. Laboratory diagnosis in ophthalmology. New York: Macmillan; 1987. p.90-107.

5. Wolley RC, Dembitzer HM, Herz F, Schreiber K, Koss LG. The use of a slide spinner in the analysis of cell dispersion. J Histochem Cytochem 1976; 24:11-5.

6. Leif RC, Ingram D, Clay C, Bobbitt D, Gaddis R, Leif SB, Nordqvist S. Optimization of the binding of dissociated exfoliated cervico-vaginal cells to glass microscope slides. J Histochem Cytochem 1977;25:538-43.

7. Lillie RD. Histopathologic technic. Philadelphia, Blakiston; [1948].

8. Tomimatsu P. Citologia conjuntival e corneana. In: Belfort Jr R, Almada A, Tomimatsu P. Doenças externas oculares: aspectos técnicos práticos e interpretação clínica dos achados laboratoriais. São Paulo: Roca; 1981. p.3-14.

9. Herbert H. Preliminary note on the pathology and diagnosis of spring catarrh. Br Med J 1903;2:735.

10. Friedlaender MH. Ocular allergy. Int Ophthalmol Clin 1985;25:35-41.

11. Friedlaender MH. Ocular allergy. J Allergy Clin Immunol 1985;76:645-57.

12. Naib ZM, Clepper AS, Elliott SR. Exfoliative cytology as an aid in the diagnosis of ophthalmic lesions. Acta Cytol 1967;11:295-303.
13. Bonini S, Bonini S, Vecchione A, Naim DM, Allansmith MR, Balsano F. Inflammatory changes in conjunctival scrapings after allergen provocation in humans. J Allergy Clin Immunol 1988;82:462-9.

14. Kimura SJ, Thygeson P. The cytology of external ocular disease. Am J Ophthalmol 1955;39:137-45.

15. Melvin DM, Brooke MM. Triton X-100 in Giemsa staining of blood parasites. Stain Technol 1955;30:269-75.

16. Siegel S, Castellan Jr. NJ. Nonparametric statistics. $2^{\text {nd }}$ ed. New York: Mac Graw-Hill; 1988.399p.

17. Neumann E, Gutmann MJ, Blumenkrantz N, Michaelson IC. A review of four hundred cases of vernal conjunctivitis. Am J Ophthalmol 1959;47:166-72.

18. Buckley RJ. Vernal keratoconjunctivitis. Int Ophthalmol Clin 1988;28:303-8.

19. Power WJ, Tugal-Tutkun I, Foster CS. Long-term follow-up of patients with atopic keratoconjunctivitis. Ophthalmology 1998;105:637-42.

20. Tuft SJ, Kemeny DM, Dart JK, Buckley RJ. Clinical features of atopic keratoconjunctivitis. Ophthalmology 1991;98:150-8.

21. Naib ZM. Cytology of ocular lesions. Acta Cytol 1972;16:178-85.

22. Thygeson P. The cytology of conjunctival exudates. Am J Ophthalmol 1946; 29:1499-1512.

23. Palestine AG, Meyers SM, Fauci AS, Gallin JI. Ocular findings in patients with neutrophil dysfunction. Am J Ophthalmol 1983;95:598-604.

24. Abelson MB, Madiwale N, Weston JH. Conjunctival eosinophils in allergic ocular disease. Arch Ophthalmol 1983;101:555-6.

25. Abelson MB, Udell IJ, Weston JH. Conjunctival eosinophils in compound 48/80 rabbit model. Arch Ophthalmol 1983;101:631-3.

26. Friedlaender MH, Okumoto M, Kelley J. Diagnosis of allergic conjunctivitis. Arch Ophthalmol 1984;102:1198-9.

\section{SIMAsp Simpósio Internacional Moacyr Álvaro}

\section{2 a 14 de fevereiro de 2004}

Centro de Convenções Frei Caneca - S. Paulo - SP Miopia e Oftalmologia do Básico ao Avançado

\section{Promoção: Centro de Estudos Oftalmológicos Moacyr E. Álvaro - UNIFESP}

INFORMAC̣ÕES: Tel.: (1 1 1) 5085-2026 E-mail: ceo@oftalmo.epm.br 